Research Article

\title{
A canonical correlation analysis of the association between carcass and ham traits in pigs used to produce dry-cured ham
}

\author{
Henrique T. Ventura ${ }^{1}$, Paulo S. Lopes ${ }^{1}$, José V. Peloso ${ }^{1}$, Simone E.F. Guimarães ${ }^{1}$, \\ Antonio Policarpo S. Carneiro ${ }^{2}$ and Paulo L.S. Carneiro ${ }^{3}$ \\ ${ }^{1}$ Departamento de Zootecnia, Universidade Federal de Viçosa, Viçosa, MG, Brazil. \\ ${ }^{2}$ Departamento de Estatística, Universidade Federal de Viçosa, Viçosa, MG, Brazil. \\ ${ }^{3}$ Departamento de Ciências Biológicas, Universidade Estadual do Sudoeste da Bahia, Jequié, BA, Brazil.
}

\begin{abstract}
The association between carcass and ham traits in a pig population used to produce dry-cured ham was studied using canonical correlation analysis. The carcass traits examined were hot carcass weight (HCW), backfat thickness (BT) and loin depth (LD), and the ham traits studied were gross ham weight (GHW), trimmed ham weight (THW), ham inner layer fat thickness (HIFT), ham outer layer fat thickness (HOFT), $\mathrm{pH}(\mathrm{pH})$ and the Göfo value. Carcass and ham traits are not independent. The canonical correlations $(r)$ between the carcass and ham traits at $130 \mathrm{~kg}$ were $0.77,0.24$ and 0.20 for the first, second and third canonical pair, respectively, and were all significant $(p<0.01)$ by the Wilks test. The corresponding canonical correlations between the three canonical variate pairs for the carcass and ham traits at $160 \mathrm{~kg}$ were $0.88,0.42$ and 0.14 , respectively $(\mathrm{p}<0.05$ for all, except the third). The correlations between the traits and their canonical variate showed an association among HCW, GHW and THW, and between BT and HOFT. These results indicate that carcass traits should be used to cull pigs that are not suitable for dry-cured ham production.
\end{abstract}

Key words: canonical correlation, carcass, ham, pig.

Received: February 4, 2011; Accepted: April 28, 2011.

\section{Introduction}

Selecting pigs for dry-cured ham production requires various measurements on the ham in its rough state. Usual measurements include ham weight, trimmed ham weight, $\mathrm{pH}$, meat color, intramuscular fat and the inner and outer layer fat thickness (Candek-Potokar et al., 2002; Peloso et al., 2010). Several authors have reported an association between ham traits and end product quality after the ham curing process. Ham weight and fat thickness are related to losses in the curing process (Bosi and Russo, 2004). The internal fat content influences the flavor (Wood et al., 1992) while the $\mathrm{pH}$ influences the dry-cured ham quality (Peloso et al., 2010).

Measuring the ham traits involves procedures that require specific equipment and trained personnel, in addition to a considerable amount of time to obtain the measurements, as can be appreciated in the methodologies reported by Candek-Potokar et al. (2002) and Peloso et al. (2010). A potentially viable solution for eliminating the need to obtain these measurements in all individuals of a population of pigs intended for dry-cured ham production would be to

Send correspondence to Paulo S. Lopes. Departamento de Zootecnia, Universidade Federal de Viçosa, 36570-000 Viçosa, MG, Brazil. E-mail: plopes@ufv.br. use the information from an easily measured group of carcass traits that are correlated with the ham traits as this would allow prior culling of animals that did not meet the established standards.

Carcass typing measurements, such as hot carcass weight, backfat thickness and loin depth, can be obtained in pigs without great difficulty and are correlated with some of the measurements used in ham evaluation (Swatland, 1984; Beattie et al., 1999; Virgili et al., 2003; DoeschlWilson et al., 2005, Peloso et al., 2010). Hence, the relationships among the carcass and ham traits could be useful in ascertaining the viability of using only the data from the first group of measurements when selecting the best individuals for dry-cured ham production.

Canonical correlation (Weiss, 1972; Barbosa et al., 2005 ) is a technique that establishes the interrelation between two sets of variables, in addition to quantifying the percentage of variance common to the two groups. Canonical correlation analysis is a multivariate analysis technique in which the maximum correlation between two sets of variables is estimated by linear combinations of the original variables (canonical variates) (Cruz et al., 2004). The first group is generally considered to be established by $p$ traits and the second by $q$ traits. The number of canonical correla- 
tions is equal to the smallest number of traits that constitute one of the complexes ( $p$ or $q$ ) and its magnitude decreases with the order in which these are estimated. However, in absolute value, the first coefficient of canonical correlation is always greater than or equal to any simple or multiple correlation coefficient among the traits of the first and second groups.

The objective of this study was therefore to use canonical correlation analysis to examine the association among carcass and ham traits of a pig population intended for dry-cured ham production.

\section{Material and Methods}

The data used in this study were derived from five genetic groups of pigs produced on a farm in the state of Santa Catarina in southern Brazil. The following genetic groups were used: DUDU $=$ Duroc, DULA $=$ Duroc $\mathrm{x}$ Landrace, DUWI $=$ Duroc $\mathrm{x}$ Large White, DULL $=$ Duroc $\mathrm{x}$ (Landrace $\mathrm{x}$ Large White) and WIWI $=$ Large White.

After weaning at 28 days of age, the piglets were transferred weekly in batches of 20 to the nursery and growing barns and separated based on their genetic group into pens of mixed gender. The animals remained in these facilities until they reached 83 days of age and a mean weight of $48.3 \mathrm{~kg}$. They were then transferred to the finishing barns and kept in groups of 5-8 animals per stall according to their genetic group and gender. Throughout the experiment the pigs received a corn and soybean meal-based diet ad libitum (Peloso et al., 2010). The pigs were harvested in two periods (at $130 \mathrm{~kg}$ and $160 \mathrm{~kg}$ live weight). The animals in the Duroc (DUDU) genetic group were tested only at $130 \mathrm{~kg}$ harvest weight (HW) since animals with $160 \mathrm{~kg} \mathrm{HW}$ are inappropriate for industrial use because of their low feeding efficiency at this later stage, excess carcass fat, and the occurrence of deep-seated hair on the hams.

The pigs were harvested using the routine standard operational procedures of the plant, according to the technical standards of the Federal Inspection Service (SIF) of the Brazilian Ministry of Agriculture, Livestock and Food Supply. The carcass traits used included hot carcass weight (HCW), backfat thickness (BT) and loin depth (LD) and the ham traits were gross ham weight (GHW), trimmed ham weight (THW), ham inner layer fat thickness (HIFT), ham outer layer fat thickness (HOFT), $\mathrm{pH}$ at $24 \mathrm{~h}$ post-mortem $(\mathrm{pH})$ and the ham color by objective surface light reflectance of the semimembranosus muscle at $24 \mathrm{~h}$ after harvest (Göfo value, ranging from $0=$ pale to $100=$ dark). Details of the measurements of these traits are described by Peloso et al. (2010).

The analyses were done separately for each harvest weight group (130 kg and $160 \mathrm{~kg}$ ) and pigs without the measure in all of the traits assessed within the group were excluded. Table 1 shows the number of individuals analyzed in each harvest weight, together with the means and
Table 1 - Mean values and coefficients of variation for various production traits at two harvest weights in pigs.

\begin{tabular}{lccccc}
\hline \multirow{2}{*}{ Traits } & \multicolumn{2}{c}{$130 \mathrm{~kg}(\mathrm{n}=396)$} & & \multicolumn{2}{c}{$160 \mathrm{~kg}(\mathrm{n}=91)$} \\
\cline { 2 - 3 } \cline { 5 - 6 } & Mean & CV $(\%)$ & & Mean & CV $(\%)$ \\
\hline HCW (kg) & 94.46 & 4.82 & & 117.97 & 6.19 \\
BT (mm) & 18.69 & 21.78 & & 23.51 & 23.36 \\
LD (mm) & 56.39 & 10.57 & & 53.69 & 11.53 \\
GHW (kg) & 15.19 & 5.39 & & 18.77 & 7.02 \\
THW (kg) & 10.85 & 5.38 & & 12.98 & 7.39 \\
pH & 5.58 & 2.82 & & 5.67 & 2.38 \\
Göfo value* & 55.39 & 8.69 & & 56.45 & 6.16 \\
HIFT (mm) & 4.40 & 62.43 & & 6.40 & 65.68 \\
HOFT (mm) & 26.59 & 33.53 & & 22.94 & 25.12 \\
\hline
\end{tabular}

BT - backfat thickness, GHW - gross ham weight, LD - loin depth, HCW hot carcass weight, HIFT - ham inner layer fat thickness, HOFT - ham outer layer fat thickness, $\mathrm{pH}$ - $\mathrm{pH} 24 \mathrm{~h}$ post-mortem, THW - trimmed ham weight. *Range from 0 (pale) to 100 (dark).

coefficients of variation for carcass and ham traits. Prior to analysis, the data was adjusted for the fixed effects of gender and genetic group by the least squares method. The variables were then standardized to allow expression in different scales, as described by Cruz et al. (2004).

The number of conditions (NC) test described by Montgomery and Peck (1992) was used to detect the effect of multicolinearaity or linear correlation among the variables that could lead to the formation of singular or illconditioned matrices. Since the NC for all the data groups was less than 100 no variable was discarded. Canonical correlation analysis was used to evaluate the relationships between the groups of carcass and ham traits by the CANCORR procedure of the SAS program for Windows version 9.1, based on the phenotypic correlation matrix among the nine traits used in this study. The canonical correlation coefficients and the correlation between the original variables and related canonical variate were estimated. The Wilks statistic was used to test the significance of the canonical correlation, as described by Barbosa et al. (2005).

\section{Results and Discussion}

Table 2 shows that there was a high positive correlation among hot carcass weight ( $\mathrm{HCW}$ ), gross ham weight (GHW) and trimmed ham weight (THW), and simple correlation between backfat thickness (BT) and ham outer layer fat thickness (HOFT), as well as positive correlation between loin depth (LD) and trimmed ham weight (TH) for harvest at $130 \mathrm{~kg}$ and $160 \mathrm{~kg}$ (Table 2). These correlations revealed an association among the carcass and ham traits.

The canonical correlation (r) between the sets of carcass and ham traits for harvest at $130 \mathrm{~kg}$ was $0.77,0.24$ and 0.20 for the first, second and third canonical variate pairs, respectively, and all were significant $(p<0.01)$ by the 
Table 2 - Simple correlation coefficients ( $\mathrm{r}$ ) among the carcass and ham traits for harvest at $130 \mathrm{~kg}$ (below the diagonal) and $160 \mathrm{~kg}$ (above the diagonal).

\begin{tabular}{lccccccccc}
\hline & HCW $(\mathrm{kg})$ & $\mathrm{BT}(\mathrm{mm})$ & $\mathrm{LD}(\mathrm{mm})$ & $\mathrm{GHW}(\mathrm{kg})$ & $\mathrm{THW}(\mathrm{kg})$ & $\mathrm{pH}$ & Göfo value $^{*}$ & HIFT $(\mathrm{mm})$ & HOFT $(\mathrm{mm})$ \\
\hline HCW $(\mathrm{kg})$ & 1 & 0.08 & 0.05 & $0.85^{* *}$ & $0.75^{* *}$ & -0.10 & 0.03 & 0.11 & 0.11 \\
BT (mm) & 0.15 & 1 & -0.84 & 0.03 & -0.15 & -0.02 & 0.01 & 0.13 & $0.24^{*}$ \\
LD (mm) & 0.07 & -0.61 & 1 & 0.08 & $0.28^{* *}$ & -0.08 & -0.02 & -0.15 & $-0.18^{* *}$ \\
GHW (kg) & $0.75^{* *}$ & 0.01 & $0.13^{*}$ & 1 & $0.79^{* *}$ & -0.20 & -0.05 & -0.02 & 0.01 \\
THW (kg) & $0.66^{*}$ & -0.09 & $0.15^{* *}$ & $0.84^{* *}$ & 1 & -0.14 & 0.11 & -0.15 & 0.06 \\
pH & -0.03 & -0.04 & 0.09 & 0 & -0.03 & 1 & $0.50^{* *}$ & $0.23^{*}$ & -0.01 \\
Göfo value & 0.04 & 0.05 & 0.07 & 0 & -0.05 & $0.35^{* *}$ & 1 & $0.25^{*}$ & 0.14 \\
HIFT (mm) & 0.07 & 0.04 & -0.06 & -0.01 & -0.09 & 0.04 & $0.20^{* *}$ & 1 & 0.07 \\
HOFT (mm) & 0.09 & $0.11^{*}$ & $-0.19^{* *}$ & -0.07 & -0.04 & 0.01 & $-0.27^{* *}$ & $-0.15^{* *}$ & 1 \\
\hline
\end{tabular}

BT - backfat thickness, GHW - gross ham weight, LD - loin depth, HCW - hot carcass weight, HIFT - ham inner layer fat thickness, HOFT - ham outer layer fat thickness, $\mathrm{pH}$ - pH 24 h post-mortem, THW - trimmed ham weight. "Range from 0 (pale) to 100 (dark). *p $<0.05$ and ${ }^{* *}$ p $<0.01$ (Student's $t$-test).

Wilks test (Table 3). The canonical correlation (r) between the sets of carcass and ham traits for harvest at $160 \mathrm{~kg}$ for the three canonical variate pairs was $0.88,0.42$ and 0.14 , respectively (Table 4); the last of these, corresponding to the third canonical variate pair, was the only one that was not significant by the Wilks test.

When the simple correlation coefficients (Table 2) were compared with the canonical correlation values (Tables 3 and 4) the latter values for the first canonical variate pairs, for harvest at $130 \mathrm{~kg}$ (Table 3) and at $160 \mathrm{~kg}$ (Table 4), were greater than any simple correlation coefficient

Table 3 - Standardized canonical coefficients of variates, canonical correlation ( $\mathrm{r}$ ) between two sets of traits, significance test $(\mathrm{F})$ for the canonical correlation and squared canonical correlation $\left(\mathrm{r}^{2}\right)$ between carcass and ham traits for harvest at $130 \mathrm{~kg}$, for the three canonical variate pairs.

\begin{tabular}{lccc}
\hline & \multicolumn{3}{c}{ Standardized canonical coefficients } \\
\cline { 2 - 4 } Traits & $1^{\circ}$ & $2^{\circ}$ & $3^{\circ}$ \\
\hline Carcass & & & \\
HCW (kg) & 1.008 & 0.096 & -0.200 \\
BT (mm) & -0.158 & 0.646 & 1.110 \\
LD (mm) & 0.018 & -0.454 & 1.199 \\
Ham & & & \\
GHW (kg) & 0.790 & 1.074 & 0.959 \\
THW (kg) & 0.228 & -1.116 & -1.109 \\
pH & -0.037 & -0.410 & 0.209 \\
Göfo value & 0.038 & 0.254 & 0.506 \\
HIFT (mm) & 0.096 & 0.230 & -0.443 \\
HOFT (mm) & -0.060 & 0.734 & -0.352 \\
$\mathrm{r}$ & 0.77 & 0.24 & 0.20 \\
F & $26.29 * *$ & $4.07 * *$ & $3.99 * *$ \\
$\mathrm{r}^{2}$ & 0.60 & 0.06 & 0.04 \\
\hline
\end{tabular}

BT - backfat thickness, GHW - gross ham weight, LD - loin depth, HCW hot carcass weight, HIFT - ham inner layer fat thickness, HOFT - ham outer layer fat thickness, $\mathrm{pH}$ - $\mathrm{pH} 24 \mathrm{~h}$ post-mortem, THW - trimmed ham weight. "Range from 0 (pale) to 100 (dark). ${ }^{* *} \mathrm{p}<0.01$ (F test). among the carcass and ham traits within the corresponding harvest weight (130 kg or $160 \mathrm{~kg}$ ) (Table 2). These results were expected since according to Cruz et al. (2004) the absolute value of the canonical correlation coefficient for the first canonical variate pairs is always greater than or equal to any simple or multiple correlation coefficient among the traits of the first and second groups.

The squared canonical correlation coefficients $\left(r^{2}\right)$ (Tables 3 and 4) that indicated the proportion of variance common to the two groups of traits were $0.60,0.06$ and 0.04 for the first, second and third canonical variate pairs, re-

Table 4 - Standardized canonical coefficients of variates, canonical correlation ( $\mathrm{r}$ ) between two sets of traits, significance test (F) for the canonical correlation and squared canonical correlation $\left(\mathrm{r}^{2}\right)$ between carcass and ham traits for harvest at $160 \mathrm{~kg}$, for the three canonical variate pairs.

\begin{tabular}{lccc}
\hline & \multicolumn{3}{c}{ Standardized canonical coefficients } \\
\cline { 2 - 4 } Traits & $1^{\circ}$ & $2^{\circ}$ & $3^{\circ}$ \\
\hline Carcass & & & \\
HCW (kg) & 0.9938 & 0.0996 & -0.2482 \\
BT (mm) & 0.0018 & 0.1730 & 1.9127 \\
LD (mm) & 0.0691 & -0.8478 & 1.7186 \\
Ham & & & \\
GHW (kg) & 0.7259 & 1.1664 & -0.6215 \\
THW (kg) & 0.3237 & -1.380 & 0.5289 \\
pH & 0.0703 & 0.1405 & -0.5301 \\
Göfo value & -0.0621 & 0.0784 & -0.1115 \\
HIFT (mm) & 0.1626 & 0.0882 & -0.0295 \\
HOFT (mm) & 0.0927 & 0.5456 & 0.7351 \\
$\mathrm{r}$ & 0.88 & 0.42 & 0.14 \\
F & $11.04^{* *}$ & $1.94 *$ & $0.44^{\mathrm{ns}}$ \\
$\mathrm{r}^{2}$ & 0.78 & 0.18 & 0.02 \\
\hline
\end{tabular}

BT - backfat thickness, GHW - gross ham weight, LD - loin depth, HCW hot carcass weight, HIFT - ham inner layer fat thickness, HOFT - ham outer layer fat thickness, $\mathrm{pH}$ - $\mathrm{pH} 24 \mathrm{~h}$ post-mortem, THW - trimmed ham weight. "Range from 0 (pale) to 100 (dark). ${ }^{*} \mathrm{p}<0.05$ and ${ }^{* *} \mathrm{p}<0.01$ (F test). ns - non-significant. 
spectively, for the $130 \mathrm{~kg} \mathrm{HW}$ (Table 3) and $0.78,0.18$ and 0.02 (Table 4) for the $160 \mathrm{~kg} \mathrm{HW}$. These results indicate that the carcass and ham traits were not independent and that there were intergroup relationships.

The standardized canonical coefficients (canonical weights) indicate how much each variable contributed to the corresponding canonical variate (Akbas and Takma, 2005). In the first canonical variate pair, absolute predominance was observed for $\mathrm{HCW}$ in the carcass traits, and for GHW and THW in the ham traits, for harvest at $130 \mathrm{~kg}$ (Table 3) and $160 \mathrm{~kg}$ (Table 4). The second canonical variate pair had greater standardized canonical coefficients for BT and LD in the carcass traits, and GHW and THW had a greater influence in the ham traits, for harvest at $130 \mathrm{~kg}$ (Table 3) and $160 \mathrm{~kg}$ (Table 4).

In the third canonical variate pair, BT and LD yielded the greatest coefficients for the carcass traits whereas GHW and THW predominated among the ham traits for harvest at $130 \mathrm{~kg}$ (Table 3). Although the standardized canonical coefficients indicate participation of the original variables in their respective canonical variate, they cannot be used to conclude accurately on this relationship because the standardized canonical coefficients are influenced by the general structure of the data (Akbas and Takma, 2005). According to Cruz et al. (2004), interpretation of the correlation between the original variable and the related canonical variate (Tables 5 and 6 ) is a better alternative for identifying the nature of the relationships represented by the canonical correlation coefficient.

For the first canonical variate pair, the HCW showed greater correlation with its respective canonical variate and values close to unity among carcass traits for harvest at $130 \mathrm{~kg}$ (Table 5) and $160 \mathrm{~kg}$ (Table 6). In the ham traits, the greatest correlation for the first canonical variate pair with

Table 5 - Correlation between the carcass traits and their respective canonical variates $(\mathrm{U})$ and between the ham traits and their respective canonical variates $(V)$ for harvest at $130 \mathrm{~kg}$, for the three canonical variate pairs.

\begin{tabular}{lccc}
\hline Trait & U1 & U2 & U3 \\
\hline HCW $(\mathrm{kg})$ & 0.9858 & 0.1613 & 0.0465 \\
BT $(\mathrm{mm})$ & -0.0189 & 0.9349 & 0.3545 \\
LD $(\mathrm{mm})$ & 0.1819 & -0.8384 & 0.5138 \\
\hline & $\mathrm{V} 1$ & $\mathrm{~V} 2$ & $\mathrm{~V} 3$ \\
\hline GHW $(\mathrm{kg})$ & 0.9851 & 0.0795 & 0.0562 \\
THW (kg) & 0.8864 & -0.2666 & -0.2730 \\
pH & -0.0260 & -0.2795 & 0.3931 \\
Göfo value & 0.0497 & 0.0136 & 0.6377 \\
HIFT (mm) & 0.0783 & 0.2445 & -0.1914 \\
HOFT (mm) & -0.1501 & 0.6030 & -0.4382 \\
\hline
\end{tabular}

BT - backfat thickness, GHW - gross ham weight, LD - loin depth, HCW hot carcass weight, HIFT - ham inner layer fat thickness, HOFT - ham outer layer fat thickness, $\mathrm{pH}$ - $\mathrm{pH} 24 \mathrm{~h}$ post-mortem, THW - trimmed ham weight. "Range from 0 (pale) to 100 (dark).
Table 6 - Correlation between the carcass traits and their respective canonical variates $(\mathrm{U})$ and between the ham traits and their respective canonical variates $(V)$ for harvest at $160 \mathrm{~kg}$, for the three canonical variate pairs.

\begin{tabular}{lccc}
\hline Trait & $\mathrm{U} 1$ & $\mathrm{U} 2$ & $\mathrm{U} 3$ \\
\hline HCW $(\mathrm{kg})$ & 0.9977 & 0.0671 & -0.0070 \\
BT $(\mathrm{mm})$ & 0.0204 & 0.8970 & 0.4416 \\
LD $(\mathrm{mm})$ & 0.1214 & -0.9886 & 0.0893 \\
\hline & $\mathrm{V} 1$ & $\mathrm{~V} 2$ & $\mathrm{~V} 3$ \\
\hline GHW $(\mathrm{kg})$ & 0.9682 & 0.0455 & -0.0813 \\
THW $(\mathrm{kg})$ & 0.8615 & -0.4511 & 0.1485 \\
pH & -0.1221 & 0.1460 & -0.5500 \\
Göfo value & 0.0278 & 0.0471 & -0.1943 \\
HIFT (mm) & 0.1080 & 0.3702 & -0.1968 \\
HOFT (mm) & 0.1193 & 0.4903 & 0.7508 \\
\hline
\end{tabular}

BT - backfat thickness, GHW - gross ham weight, LD - loin depth, HCW hot carcass weight, HIFT - ham inner layer fat thickness, HOFT - ham outer layer fat thickness, $\mathrm{pH}$ - $\mathrm{pH} 24 \mathrm{~h}$ post-mortem, THW - trimmed ham weight. "Range from 0 (pale) to 100 (dark).

the corresponding canonical variate was observed for GHW and THW at both $130 \mathrm{~kg}$ (Table 5) and $160 \mathrm{~kg}$ (Table 6). These findings indicated that HCW, GHW and THW were positively correlated.

Considering the second canonical variate pair, the carcass traits that correlated best with their respective canonical variate were BT and LD; the latter had negative values for the carcass traits for harvest at $130 \mathrm{~kg}$ (Table 5) and $160 \mathrm{~kg}$ (Table 6). For ham traits, the best correlation with the corresponding canonical variate was for HOFT at harvest of $130 \mathrm{~kg}$ (Table 5) and $160 \mathrm{~kg}$ (Table 6). These results indicated that $\mathrm{BT}$ and LD correlated positively and negatively, respectively, with HOFT.

The carcass traits BT and LD also showed the greatest correlation with their respective canonical variate in the third canonical pair, whereas the ham trait light reflectance (color) of the semimembranosus muscle (Göfo value) showed the greatest correlation with its respective canonical variate in the third canonical pair (Table 5). Both BT and LD were correlated with the Göfo value. The correlation between the carcass and ham traits and their respective canonical variate in the third canonical pair was significant only for harvest at $130 \mathrm{~kg}$; no significant canonical correlations were observed for harvest at $160 \mathrm{~kg}$.

Together, the results of this study indicate that hot carcass weight (HCW), backfat thickness (BT) and loin depth (LD) are associated with the traits gross ham weight (GHW), trimmed ham weight (THW) and ham outer layer fat thickness (HOFT). These ham traits directly influence the quality and efficiency of the dry-cured ham production process and are therefore determinants of successful drycured ham production. Some authors have reported that backfat thickness and ham weight are negatively correlated with losses during the maturation process (Candek-Potokar 
et al., 2002; Bosi and Russo, 2004). According to Bosi and Russo (2004), low fat proportions in the carcass and ham are associated with undesirable sensory traits in dry-cured ham.

Our findings indicate that the carcass traits considered here could be used as criteria for prior culling of pigs that do not meet the established standards, thereby eliminating the need to obtain ham measurements in all of the pig population intended for dry-cured ham production. However, it should be remembered that correlations estimated only from the phenotypic correlations do not necessarily reflect the genetic nature of this link. Phenotypic correlations result from genetic and environmental causes. The extent of such correlations depends on genetic and environmental correlations, especially the heritability of each trait, which determines the importance of the genetic and environmental causes that affect the phenotypic correlation. If both traits have low heritabilities, then the phenotypic correlation is determined mainly by the environmental correlation, but if they have high heritabilities, then genetic correlation is more important (Falconer and Mackay, 1996; Lopes, 2005). Consequently, inferences based only on results obtained from phenotypic correlations, as in the present study, should be considered with caution and applied only to this population.

To conclude, the carcass and ham traits studied here were not independent since there was an association between hot carcass weight (HCW), gross ham weight (GHW) and trimmed ham weight (THW), and between backfat thickness (BT) and ham outer layer fat thickness (HOFT). The carcass traits HCW, BT and LD can be used for early culling of pigs that do not meet the standards established for dry-cured ham production, thereby eliminating the need to obtain ham measurements from all of the animals. This prior culling would save time and labor during dry-cured ham production.

\section{Acknowledgments}

This work was supported by Conselho Nacional de Desenvolvimento Científico e Tecnológico (CNPq) and Fundação de Amparo à Pesquisa do Estado de Minas Gerais (FAPEMIG).

\section{References}

Akbas Y and Takma Ç (2005) Canonical correlation analysis for studying the relationship between egg production traits and body weight, egg weight and age at sexual maturity in layers. Czech J Anim Sci 50:163-168.

Barbosa L, Lopes PS, Regazzi AJ, Guimarães SEF and Torres RA (2005) Estudo da associação entre características de desempenho e de carcaça de suínos por meio de correlação canônica. Rev Bras Zootec 34:2218-2224 (Abstract in English).

Beattie VE, Weatherup RN, Moss BW and Walker N (1999) The effect of increasing carcass weight of finishing boars and gilts on joint composition and meat quality. Meat Sci 52:205-211.

Bosi P and Russo V (2004) The production of the heavy pig for high quality processed products. Ital J Anim Sci 3:309-321.

Candek-Potokar M, Monin G and Zlender B (2002) Pork quality, processing, and sensory characteristics of dry-cured hams as influenced by Duroc crossing and sex. J Anim Sci 80:988996.

Cruz CD, Regazzi AJ and Carneiro PCS (2004) Modelos Biométricos Aplicados ao Melhoramento Genético. 3rd edition. Universidade Federal de Viçosa, Viçosa, 480 pp.

Doeschl-Wilson AB, Green DM, Fisher AV, Carroll SM, Schofield CP and Whittemore CT (2005) The relationship between body dimensions of living pigs and their carcass composition. Meat Sci 70:229-240.

Falconer DS and Mackay TFC (1996) Introduction to Quantitative Genetics. 4th edition. Longman, Harlow, $464 \mathrm{pp}$.

Lopes PS (2005) Teoria do Melhoramento Animal. FEPMVZ, Belo Horizonte, 118 pp.

Montgomery DC and Peck EA (1992) Introduction to Linear Regression Analysis. 2nd edition. John Wiley Sons, New York, $527 \mathrm{pp}$.

Peloso JV, Lopes PS, Gomide LAM, Guimarães SEF and Carneiro PLS (2010) Carcass and ham quality characteristics of heavy pigs from different genetic groups intended for the production of dry-cured hams. Meat Sci 86:371-376.

Swatland HJ (1984) Structure and Development of Meat Animals. Prentice-Hall, Englewood Cliffs, 436 pp.

Virgili R, Degni M, Schivazappa C, Faet V, Poletti E, Marchetto G, Pacchioli MT and Mordenti A (2003) Effect of age at slaughter on carcass traits and meat quality of Italian heavy pigs. J Anim Sci 81:2448-2456.

Weiss DJ (1972) Canonical correlation analysis in counselling psychology research. J Couns Psychol 19:241-252.

Wood JD, Warriss PD and Enser MB (1992) Effects of production factors on meat quality in pigs. In: Johnston DE, Knight MK and Ledward DA (eds) The Chemistry of Muscle-Based Foods. Royal Society of Chemistry, Cambridge, pp 3-15.

Associate Editor: Bertram Brenig

License information: This is an open-access article distributed under the terms of the Creative Commons Attribution License, which permits unrestricted use, distribution, and reproduction in any medium, provided the original work is properly cited. 